\title{
Outcomes of a multicentre randomised clinical trial of etanercept to treat ankylosing spondylitis
}

\author{
A Calin, B A C Dijkmans, P Emery, M Hakala, J Kalden, M Leirisalo-Repo, E M Mola, \\ C Salvarani, R Sanmartí, J Sany, J Sibilia, J Sieper, S van der Linden, E Veys, \\ A M Appel, $S$ Fatenejad
}

See end of article for authors' affiliations

\section{Correspondence to:}

Dr A Calin, Holmpatrick,

Weston Road, Bath BAl

2XU, UK; calinandrei@

hotmail.com

Accepted 23 May 2004

Published Online First

2 September 2004

Objective: A double blind, randomised, placebo controlled study to evaluate the safety and efficacy of etanercept to treat adult patients with ankylosing spondylitis (AS).

Methods: Adult patients with AS at 14 European sites were randomly assigned to $25 \mathrm{mg}$ injections of etanercept or placebo twice weekly for 12 weeks. The primary efficacy end point was an improvement of at least $20 \%$ in patient reported symptoms, based on the multicomponent Assessments in Ankylosing Spondylitis (ASAS) response criteria (ASAS 20). Secondary end points included ASAS 50 and ASAS 70 responses and improved scores on individual components of ASAS, the Bath Ankylosing Spondylitis Disease Activity Index (BASDAl), acute phase reactants, and spinal mobility tests. Safety was evaluated during scheduled visits.

Results: Of 84 patients enrolled, 45 received etanercept and 39 received placebo. Significantly more etanercept patients than placebo patients responded at the ASAS 20 level as early as week 2, and sustained differences were evident up to week 12 . Significantly more etanercept patients reported ASAS 50 responses at all times and ASAS 70 responses at weeks 2, 4, and 8; reported lower composite and fatigue BASDAl scores; had lower acute phase reactant levels; and had improved spinal flexion. Etanercept was well tolerated. Most adverse events were mild to moderate; the only between-group difference was injection site reactions, which occurred significantly more often in etanercept patients. Conclusions: Etanercept is a well tolerated and effective treatment for reducing clinical symptoms and signs of AS.

A nkylosing spondylitis (AS) is an underrecognised debilitating disease predominantly affecting the spine that is characterised by axial skeletal ankylosis and inflammation at the insertions of tendons. The prevalence of AS is most clearly described in the white population where a link to the HLA-B27 antigen is best defined, and is believed to be around $0.5 \%$, with estimates ranging from $0.1 \%$ to $1.1 \%$. Peripheral joints also may be affected. The disease occurs three times more often in men than in women, ${ }^{2}$ and onset typically occurs between 20 and 40 years of age. Although AS advances slowly, damage to the spine is progressive and leads to pain, fatigue, stiffness, and functional impairment. Patients with AS often have a restricted or poor quality of life and may face a reduced life expectancy..$^{3-8}$ The socioeconomic burden of their disease can be considerable, owing to work disabilities and the use of healthcare/assistance resources, and sometimes to the patient's depressed mood or low social functioning. ${ }^{19-13}$ Current therapeutic options for AS, such as non-steroidal anti-inflammatory drugs (NSAIDs), offer temporary pain relief but confer little if any clinical benefit on spinal mobility. Disease modifying antirheumatic drugs (DMARDs), including methotrexate and sulfasalazine, may benefit peripheral arthritis but do not appear to affect the spinal involvement of AS. ${ }^{14-17}$

Tumour necrosis factor (TNF) $\alpha(\mathrm{TNF} \alpha)$, is a proinflammatory cytokine that appears to have a key role in the pathogenesis of AS. ${ }^{12}{ }^{18-22}$ Etanercept is a fully human recombinant protein, comprising two molecules of soluble TNF receptor p75 and the crystallisable fragment component of immunoglobulin Gl, which specifically binds to and neutralises TNF $\alpha .{ }^{23}{ }^{24}$ Etanercept is effective in the treatment of other TNF related diseases, including rheumatoid arthritis
(RA), juvenile chronic arthritis, and psoriatic arthritis (PsA) ${ }^{25-27}$ More recently, a phase 2 clinical study has shown that etanercept reduces disease activity in patients with spondyloarthropathies, including reactive arthritis and AS. ${ }^{28-31}$ Similar results have been reported with infliximab, a chimeric monoclonal antibody against TNF $\alpha .^{32} 33$

The current double blind, randomised, multicentre European trial examined the efficacy of etanercept to treat AS in adults, using the recently published criteria of an international consortium of experts, the Assessments in Ankylosing Spondylitis (ASAS) Working Group. ${ }^{34}$ Previous etanercept trials in AS have been conducted at both North American and European investigative sites. This study is the first conducted exclusively at European centres. Because there are potentially important differences between populations studied and in the way patients are treated in different geographical locations, it was important to this study to confirm the results of a multinational study of etanercept that was conducted concurrently. ${ }^{35}$ These trials are the first studies performed with anti-TNF biological agents using the ASAS response criteria as the primary end points.

Abbreviations: AS, ankylosing spondylitis; ASAS, Assessments in Ankylosing Spondylitis; BASDAl, Bath Ankylosing Spondylitis Disease Activity Index; BASFI, Bath Ankylosing Spondylitis Functional Index; $C R P, C$ reactive protein; DMARDs, disease modifying antirheumatic drugs; ESR, erythrocyte sedimentation rate; NSAIDs, non-steroidal antiinflammatory drugs; PsA, psoriatic arthritis; RA, rheumatoid arthritis; $\mathrm{TNF} \alpha$, tumour necrosis factor $\alpha$; VAS, visual analogue scale 


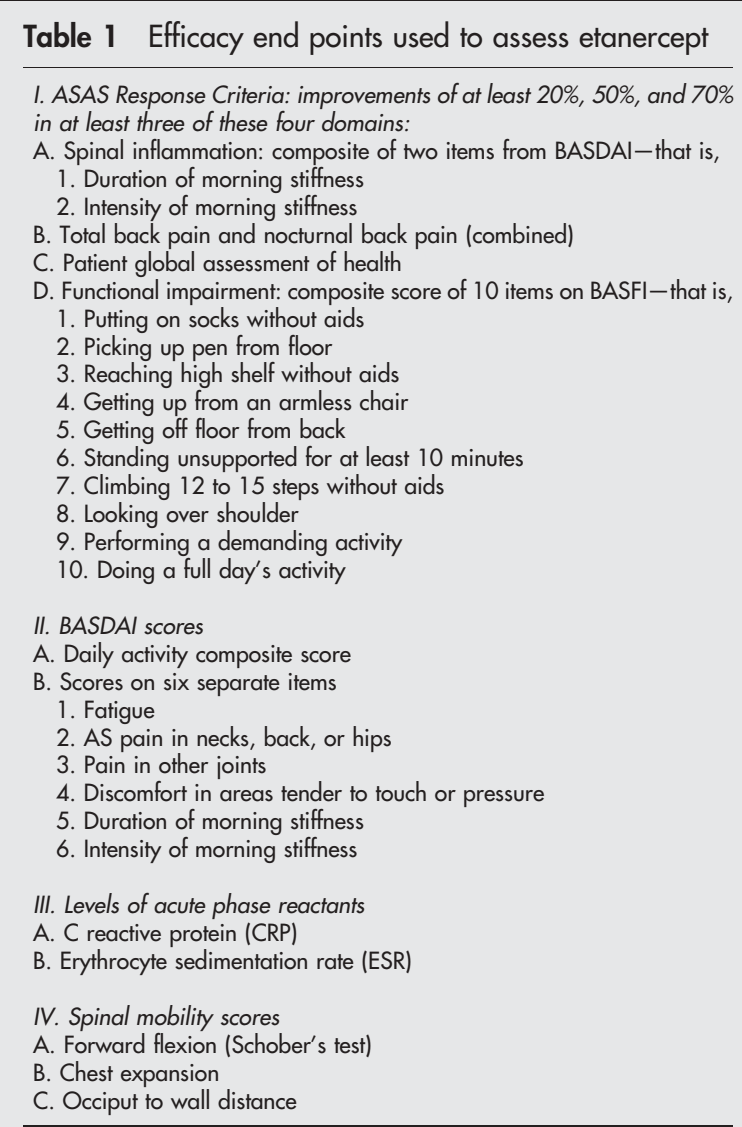

ASAS, Assessments in Ankylosing Spondylitis; BASDAl, Bath Ankylosing Spondylitis Disease Activity Index; BASFl, Bath Ankylosing Spondylitis Functional Index.

\section{PATIENTS AND METHODS \\ Study design}

A double blind, randomised, placebo controlled study was conducted to evaluate the efficacy and safety of etanercept in the treatment of adult patients with active AS. The study took place from March 2002 to August 2002 in 14 investigative centres in eight countries: Belgium, Finland, France, Germany, Italy, The Netherlands, Spain, and the United Kingdom. All centres received approval from their indepen- dent ethics committees, and all patients provided written informed consent to participate. The study included a screening period of up to 4 weeks, followed by a 12 week treatment period in which patients received etanercept or placebo. Efficacy and safety evaluations were performed at weeks 2, 4, 8, and 12.

\section{Patients}

Patients aged 18-70 years with active AS were eligible for the study. AS was diagnosed using the modified New York criteria. ${ }^{36}$ Disease activity was measured using a set of visual analogue scales (VAS) on which patients rated the severity of their symptoms from 0 (none) to 100 (most severe) in four symptom domains: (a) spinal inflammation; (b) back pain; (c) patient global assessment of disease activity; and (d) physical function. Active disease was diagnosed if the patient had an average score $\geqslant 30$ for spinal inflammation and a score $\geqslant 30$ on at least two of the other three domains.

Patients were excluded if they had complete ankylosis (fusion) of the spine; previously used TNF $\alpha$ inhibitors, including etanercept; used DMARDs other than hydroxychloroquine, sulfasalazine, or methotrexate within 4 weeks of baseline; used multiple NSAIDs; used $>10 \mathrm{mg}$ prednisone daily; or changed doses of NSAIDs or prednisone within 2 weeks of baseline. Patients were permitted to continue prestudy physiotherapy.

Patients who met eligibility criteria were stratified on the basis of concomitant DMARD use at baseline and randomly assigned to receive etanercept or placebo. The protocol did not require screening for tuberculosis.

\section{Study product}

Based on previous clinical trials of etanercept in patients with RA and PsA, a $25 \mathrm{mg}$ dose delivered subcutaneously twice weekly was selected for patients with AS. Patients self administered the product and were given individual packages containing injection supplies and instructions for storage and use. To preserve the integrity of the blind study, placebo and etanercept supplies were similar in appearance.

\section{Efficacy end points}

The clinical response to etanercept was evaluated chiefly on the basis of response criteria recommended by the ASAS Working Group, ${ }^{34}$ which covered the same four domains used in this study to assess disease activity at enrolment - that is, spinal inflammation, back pain, patient global assessment,

Table 2 Baseline demographic and descriptive characteristics

\begin{tabular}{|c|c|c|c|}
\hline Characteristic & $\begin{array}{l}\text { Total } \\
(n=84)\end{array}$ & $\begin{array}{l}\text { Placebo } \\
(n=39)\end{array}$ & $\begin{array}{l}\text { Etanercept } \\
(\mathrm{n}=45)\end{array}$ \\
\hline Age (years), mean (SD) & $43.2(10.6)$ & $40.7(11.4)$ & $45.3(9.5)^{*}$ \\
\hline Sex (men/women), \% & $79 / 21$ & $77 / 23$ & $80 / 20$ \\
\hline Race (white/other), \% & $94 / 6$ & $95 / 5$ & $93 / 7$ \\
\hline Disease duration (years), mean (SD) & $12.5(8.9)$ & $9.7(8.2)$ & $15.0(8.8)^{* *}$ \\
\hline Concomitant use of DMARD, $†$ No $(\%)$ & $32(38)$ & $16(41)$ & $16(36)$ \\
\hline Hydroxychloroquine & $1(1)$ & $1(3)$ & 0 \\
\hline Methotrexate & $11(13)$ & $5(13)$ & $6(13)$ \\
\hline Sulfasalazine & $22(26)$ & $11(28)$ & $11(24)$ \\
\hline Concomitant use of oral NSAID, No (\%) & $73(87)$ & $33(85)$ & $40(89)$ \\
\hline Concomitant use of corticosteroid, No (\%) & $13(15)$ & $6(15)$ & $7(16)$ \\
\hline \multicolumn{4}{|l|}{ Mean scores on ASAS components: } \\
\hline Spinal inflammation & 65.4 & 62.9 & 67.5 \\
\hline Nocturnal and total back pain & 58.2 & 56.1 & 60.0 \\
\hline Patient global assessment & 64.6 & 63.4 & 65.6 \\
\hline Functional impairment & 58.8 & 57.2 & 60.2 \\
\hline Mean BASDAI scores overall & 59.9 & 58.6 & 61.0 \\
\hline BASDAl scores $<40$, No (\%) & $10(12)$ & $5(13)$ & $4(9)$ \\
\hline
\end{tabular}



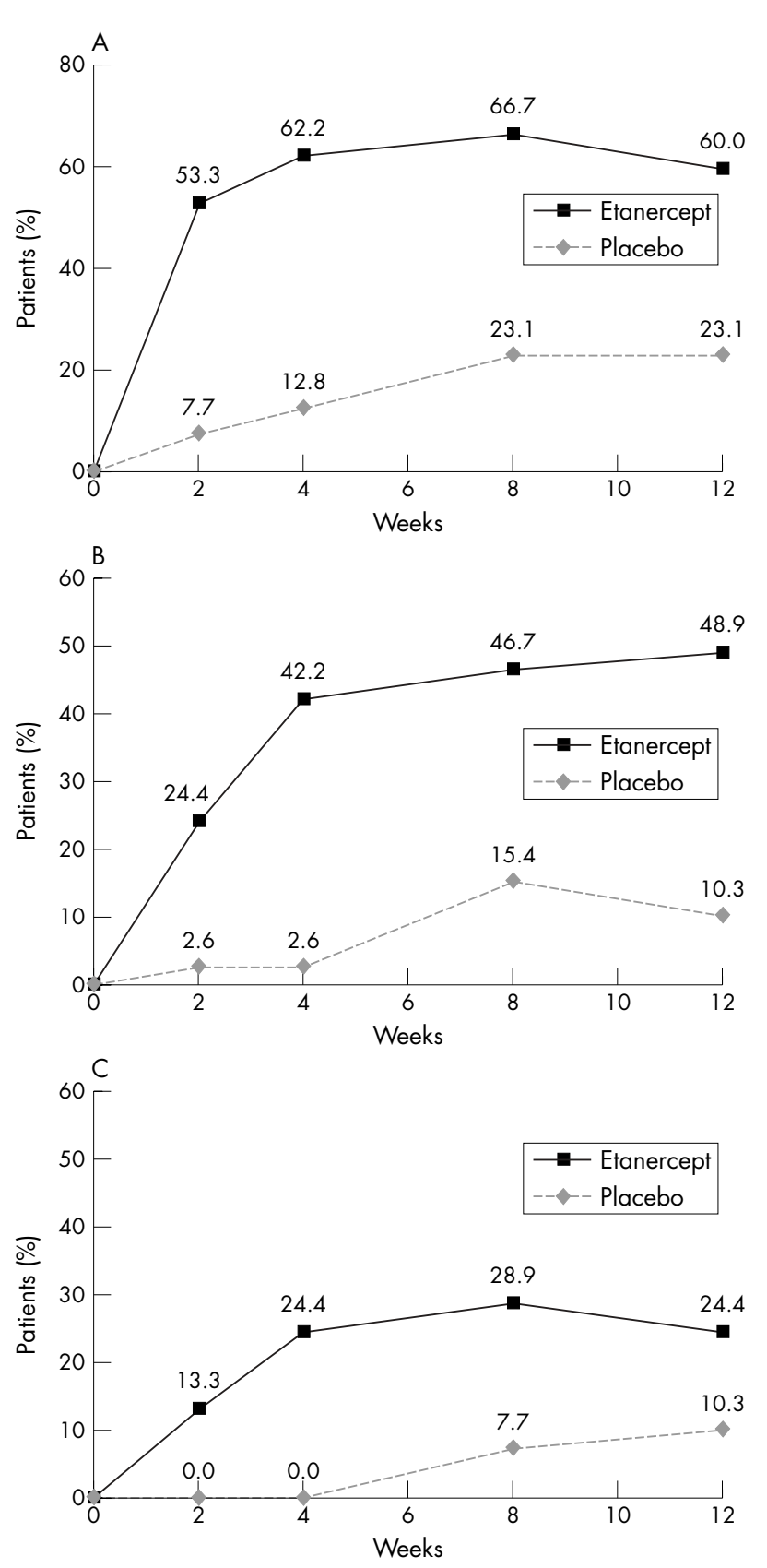

Figure 1 (A) Achievement of ASAS 20, by treatment group; (B) achievement of ASAS 50, by treatment group; (C) achievement of ASAS 70 , by treatment group.

and physical impairment. Spinal inflammation was scored as the average of two VAS questions about the duration and intensity of morning stiffness, taken from the previously validated six item Bath Ankylosing Spondylitis Disease Activity Index (BASDAI). ${ }^{37}$ Pain was scored as the average of two VAS questions about total back pain and nocturnal back pain. Patient global assessment was measured by VAS. Functional impairment was assessed by the 10 item Bath Ankylosing Spondylitis Functional Index (BASFI), a validated VAS based composite of functional ability in patients with AS. ${ }^{38}$ Table 1 shows details of the BASDAI and BASFI indexes and other efficacy end points.

The primary efficacy end point was the percentage of ASAS 20 responders after 12 weeks of treatment. ASAS 20 responders were patients who reported improvements of at least $20 \%$ and absolute improvement of at least 10 units in at least three of the four symptom domains, with no worsening in the remaining domain. Secondary end points included the percentage of ASAS 20 responders at weeks 2, 4, and 8; the percentage of patients improving $50 \%$ or more (ASAS 50) at any visit; and the percentage improving $70 \%$ or more (ASAS 70) at any visit. ASAS 50 and 70 responses also required improvement in at least three domains and no deterioration in the remaining domain. Other patient reported end points consisted of symptom improvements in individual ASAS domains and improvements on the composite BASDAI and its individual components. Effects on acute phase reactants were measured by tests for $C$ reactive protein (CRP) and erythrocyte sedimentation rate (ESR). Effects on spinal mobility were measured by Schober's test, chest expansion, and occiput to wall distance.

\section{Safety analyses}

Patients were monitored for adverse events and abnormal laboratory test results over the course of the study. Vital signs were monitored, and standard haematology, serum chemistry, and urine analysis tests were evaluated. In addition, blood samples were tested for antibody to etanercept at baseline and at week 12, using an enzyme linked immunosorbent assay (ELISA) modified from the method published earlier. $^{39}$

\section{Statistics}

Disease activity and safety analyses were based on the intention to treat population and included all patients who received at least one dose of the "blinded" test article. The last observation carried forward technique was used to handle missing data for continuous and ordinal end points. Patients who withdrew from the study prematurely were treated as non-responders at each assessment interval thereafter for ASAS and other patient reported responses. All statistical tests were two sided. The Cochrane-MantelHaenszel test, stratified by baseline DMARD use, was used to evaluate efficacy differences between the etanercept and placebo groups, and $\chi^{2}$ and Breslow-Day tests were used to evaluate direct and interactive effects of DMARDs on ASAS responses. For safety analyses, Fisher's exact test was used to compare the percentage of adverse events occurring in etanercept and placebo treated groups. Based on a previous trial, week 12 response rates of 35\% in the placebo group and $75 \%$ in the etanercept group were expected. Assuming similar response rates, this study design provided $90 \%$ power with 40 patients in each group.

\section{RESULTS}

\section{Study objective}

This study was conducted to evaluated the safety and efficacy of etanercept to treat adult patients with AS.

\section{Patient recruitment and retention}

A total of 84 patients were enrolled in the study; 45 were assigned to receive etanercept and 39 were assigned to placebo. The average age of patients was 43.2 years. Most participants were male (79\%), and the majority were white $(94 \%)$. The treatment groups had similar baseline disease activity scores and concomitant use of DMARDs, NSAIDs, and corticosteroids. Demographic characteristics were largely similar, except that etanercept patients were, on average, 5 years older than placebo patients, had had AS disease for 5 years longer (table 2), and also had significantly higher baseline CRP levels (see table 4 ).

Two patients treated with etanercept discontinued the study for non-safety reasons. The first patient discontinued after a single dose of etanercept because he did not meet the 


\begin{tabular}{|c|c|c|c|}
\hline Response measure: assessment point & $\begin{array}{l}\text { Placebo } \\
(n=39)\end{array}$ & $\begin{array}{l}\text { Etanercept } \\
(n=45)\end{array}$ & p Value* \\
\hline \multicolumn{4}{|l|}{ ASAS: Spinal inflammation } \\
\hline Baseline (mean) & 62.9 & 67.5 & \\
\hline Week 12 (\% change) & $52.6(15.9)$ & $35.6(43.3)$ & 0.003 \\
\hline \multicolumn{4}{|l|}{ ASAS: Nocturnal and total pain } \\
\hline Baseline (mean) & 56.1 & 60.0 & \\
\hline Week 12 (\% change) & $51.2(6.2)$ & $31.0(43.1)$ & 0.000 \\
\hline \multicolumn{4}{|l|}{ ASAS: Patient global assessment } \\
\hline Baseline (mean) & 63.4 & 65.6 & \\
\hline Week 12 (\% change) & $54.1(12.6)$ & $38.4(37.0)$ & 0.011 \\
\hline \multicolumn{4}{|l|}{ ASAS: Functional impairment (BASFI) } \\
\hline Baseline (mean) & 57.2 & 60.2 & \\
\hline Week 12 (\% change) & $53.9(3.4)$ & $39.6(35.4)$ & 0.000 \\
\hline \multicolumn{4}{|l|}{ BASDAl: Composite score } \\
\hline Baseline (mean) & 58.6 & 61.0 & \\
\hline Week 12 (\% change) & $50.1(13.6)$ & $33.8(43.6)$ & 0.001 \\
\hline \multicolumn{4}{|l|}{ BASDAl: Fatigue score } \\
\hline Baseline (mean) & 59.0 & 68.2 & \\
\hline Week 12 (\% change) & $54.8(-4.9)$ & $38.4(42.6)$ & 0.000 \\
\hline
\end{tabular}

inclusion criterion of active disease, and the second patient withdrew his consent 8 days after treatment was started. Both patients were treated as non-responders at subsequent times. The remaining 82 patients completed the study.

\section{Efficacy results}

Significantly more etanercept patients than placebo patients $(26(60 \%) \vee 9(23 \%) ; \mathrm{p}<0.001 ; 95 \%$ confidence interval (CI) 17.4 to $56.4 \%$ ) were ASAS 20 responders at week 12 , the primary efficacy end point. The primary end point was not significantly affected by the concomitant use of DMARDs $(p=0.632)$, nor was there an interaction effect between DMARDs and etanercept on ASAS 20 at week $12(p=0.694)$.

Significant improvements in the etanercept group were evident by week 2, the earliest assessment point, and were sustained thereafter (fig 1A). There were also significantly more responders in the etanercept group at the ASAS 50 level at all visits $(\mathrm{p}<0.01)$ and at the ASAS 70 level at weeks 2, 4, and $8(\mathrm{p}<0.05)$ (figs $1 \mathrm{~B}$ and $\mathrm{C})$. By week 12 , nearly half of the patients treated with etanercept improved $50 \%$ or more on the ASAS criteria, and a quarter of them improved $70 \%$ or more.

ASAS responses used in this study were based on the average of total and nocturnal back pain. The ASAS Working Group criteria, published after plans for this study were

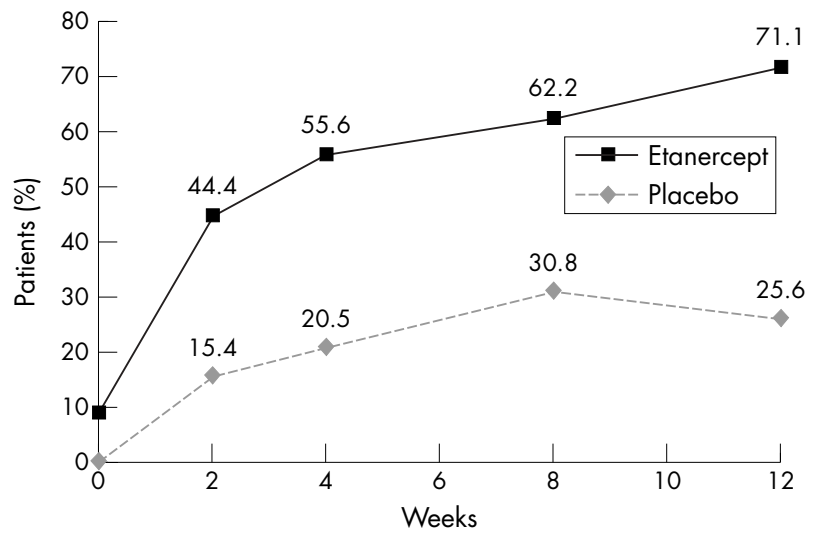

Figure 2 Percentage of patients with BASDAl scores $<40$. completed, recommended using VAS for total back pain only. Sensitivity analyses using total pain scores alone confirmed nearly identical results to those reported here.

In addition to improved responses on the overall ASAS criteria, etanercept patients significantly improved their mean scores on the individual ASAS components $(\mathrm{p}<0.01$ versus placebo). Scores of etanercept patients improved $43 \%$ on both the spinal inflammation and back pain measures, $37 \%$ on patient global assessment of disease activity, and 35\% on the functional impairment index (compared with 16\%, $6 \%, 13 \%$, and $3 \%$ improvements, respectively, for placebo patients; table 3). Although scores on individual components of the BASFI are not provided in this paper, etanercept was significantly more effective than placebo in improving nine of 10 types of functional abilities.

Scores on the BASDAI composite index and the BASDAI fatigue component improved $44 \%$ among etanercept patients $(p<0.01$ versus placebo). In addition, a post hoc analysis of BASDAI responses showed that the percentage of etanercept patients with BASDAI scores $<40$ increased from $9 \%$ at baseline to $71 \%$ at week 12 (fig 2).

Acute phase reactants, CRP and ESR, also significantly decreased in etanercept patients $(p<0.0001)$, with percentage changes of $70 \%$ and $80 \%$, respectively (table 4 ). Spinal flexion, as measured by Schober's test, improved in etanercept treated patients but not in placebo patients $(\mathrm{p}<0.01)$. Other measures of spinal mobility also improved more in etanercept patients, but the differences were not significant.

Patients in this trial had limited peripheral joint disease. Numbers of swollen and tender joints were 2 and 6 , respectively, for the entire group. Given the paucity of this information, no meaningful results on peripheral joint disease were obtained.

\section{Safety results}

Etanercept treatment was generally well tolerated. Adverse events were mostly mild to moderate, and there were no discontinuations for safety reasons. Treatment-emergent adverse events reported by $5 \%$ or more of patients in either treatment group were generally similar (table 5). As in previous studies of etanercept, injection site reactions occurred significantly more often in etanercept patients $(33 \%)$ than in patients receiving placebo $(15 \%, p<0.05)$. No antibodies to etanercept were detected. 
Table 4 Comparison of acute phase reactants and spinal mobility values before and after 12 weeks of treatment

\begin{tabular}{llll}
\hline Measurement: assessment point & Placebo & Etanercept & p Value* \\
\hline C reactive protein (mg/l) & $\mathrm{n}=39$ & $\mathrm{n}=45$ & \\
Baseline (median) & 97 & 154 & \\
Week 12 (\% change) & $117(0.0)$ & $40(69.5)$ & 0.000 \\
Erythrocyte sedimentation rate (mm/1 st h) & $\mathrm{n}=39$ & $\mathrm{n}=45$ & \\
Baseline (median) & 26.0 & 27.0 & \\
Week 12 (\% change) & $29.0(0.0)$ & $6.0(79.6)$ & 0.000 \\
Schober's test of spinal flexion (cm) & $\mathrm{n}=39$ & $\mathrm{n}=44$ & \\
Baseline (mean) & 2.8 & 2.2 & \\
Week 12 (\% change)† & $2.7(1.3)$ & $2.7(-36.0)$ & 0.009 \\
Chest expansion (cm) & $\mathrm{n}=39$ & $\mathrm{n}=44$ & \\
Baseline (mean) & 3.9 & 3.3 & \\
Week 12 (\% change)† & $4.1(-9.0)$ & $3.8(-29.9)$ & 0.870 \\
Occiput to wall distance (cm) & $\mathrm{n}=22 \ddagger$ & $\mathrm{n}=32 \ddagger$ & \\
Baseline (mean) & 4.6 & 7.3 & \\
Week 12 (\% change) & $4.0(7.2)$ & $6.2(12.5)$ & 0.065 \\
\hline
\end{tabular}

*Differences in average percentage change, baseline to week 12, by the Cochrane-Mantel-Haenszel test; tnegative percentage change from baseline indicates improvement; łincludes only patients who had a value greater than zero at baseline.

One serious adverse event was reported. An etanercept treated patient with acute myocardial infarction underwent angioplasty but continued in the study. The same patient developed grade 3 abnormality of liver function test results at the week 12 visit, which was considered to be related to concomitant indometacin treatment. The abnormalities resolved after indometacin was discontinued, and the patient completed the study.

\section{DISCUSSION}

AS is a chronic inflammatory disease, often leading to permanent spinal damage, a considerable handicap, and a poor quality of life. Current treatments for AS are inadequate for most patients, especially treatments for axial skeletal involvement.

In this 12 week study, twice weekly self administered injections of $25 \mathrm{mg}$ etanercept produced rapid, significant, and sustained improvement in multiple clinical and biological measures of AS, regardless of concomitant DMARD use. Patient improvements were evident at the 2 week visit and were sustained up to the end of the study at week 12 . Notably, the only differences between the groups at baseline were that etanercept patients were on average 5 years older, had had AS for 5 years longer than patients receiving placebo, and had higher baseline CRP levels. Given the

Table 5 Number (\%) of patients with treatment emergent adverse events or infections (occurring in $\geqslant 5 \%$ of patients in either treatment group)

\begin{tabular}{llll}
\hline Adverse event & $\begin{array}{l}\text { Placebo } \\
\text { (n=39) }\end{array}$ & $\begin{array}{c}\text { Etanercept } \\
(\mathbf{n}=45)\end{array}$ & p Value \\
\hline Injection site reactions & $6(15)$ & $15(33)$ & 0.028 \\
Haemorrhage, injection site & $4(10)$ & $8(18)$ & 0.367 \\
Headache & $4(10)$ & $6(13)$ & 0.745 \\
Nausea & $4(10)$ & $3(7)$ & 0.699 \\
Asthenia & $1(3)$ & $5(11)$ & 0.209 \\
Vertigo & $3(8)$ & 0 & 0.096 \\
Diarrhoea & $2(5)$ & $2(4)$ & 1.000 \\
Pruritus & $2(5)$ & $2(4)$ & 1.000 \\
Pain, abdomen & $2(5)$ & $1(2)$ & 0.595 \\
Paraesthesia & $2(5)$ & $1(2)$ & 0.595 \\
Arthralgia & $2(5)$ & 0 & 0.213 \\
Haemorrhage, gastrointestinal & $2(5)$ & 0 & 0.213 \\
Injury accidental & $2(5)$ & 0 & 0.213 \\
Pain, back & $2(5)$ & 0 & 0.213 \\
Throat irritation & $2(5)$ & 0 & 0.213 \\
\hline \multirow{2}{*}{ *Difference in occurrence, by Fisher's exact test. } & \\
\hline \multirow{2}{*}{. }
\end{tabular}

magnitude of the etanercept treatment response in this study, it is unlikely that these baseline differences affected the results in any significant way. Furthermore, in light of recent analyses indicating that older patients and patients with longer disease duration are less likely to have a major clinical response to TNF $\alpha$ inhibitors ${ }^{40}{ }^{41}$ this group's demonstrable response to etanercept is particularly encouraging.

The finding of multiple positive effects in this study of European patients supports the results of two other efficacy and safety studies of etanercept to treat AS. The first was a 16 week American study, which showed that etanercept was efficacious in the treatment of many symptoms reported by patients with AS, including pain, vitality, and physical function. ${ }^{28}$ The second was a 24 week multinational study that was conducted concurrently with the present study and included similar end points. ${ }^{35}$ When the ASAS benchmarks of $20 \%, 50 \%$, and $70 \%$ improvement were used, both the current study and the 24 week study found that etanercept treatment was significantly better than placebo, with robust improvements occurring as early as week 2 .

Treatment with etanercept also improved BASDAI scores; by week 12, 71\% of etanercept treated patients achieved BASDAI scores <40, which the ASAS Working Group considers as the threshold value indicating a need for antiTNF $\alpha$ treatment. ${ }^{42}$ Moreover, fatigue scores, which are felt to be an important outcome in AS, improved significantly with etanercept treatment. ${ }^{43}$ Because fatigue is associated not only with disease activity and functional ability but also with patients' global sense of wellbeing and mental health status, ${ }^{44}$ improvement in this area may lead to a better quality of life for patients with AS.

In the current study, CRP levels and ESR values significantly decreased in patients taking etanercept, which may be indicative of disease modification, not just symptomatic relief of AS. ${ }^{45-48}$ Spinal mobility, as measured by Schober's test, significantly improved in etanercept treated patients, which suggests that damage caused by AS may not be permanent. The lack of significant between-group differences in chest expansion and occiput to wall distances at the end of treatment may be due to the short duration of the study and/ or the relatively small number of patients enrolled. In the 24 week study mentioned earlier, which enrolled more patients, all three spinal mobility measures significantly improved with etanercept treatment. ${ }^{35}$ Owing to the short duration of this trial, the impressive therapeutic results must interpreted with some caution. None the less, the relative ineffectiveness of current treatments such as DMARDs and 
NSAIDs is underlined by the fact that etanercept treated patients who continued to receive these treatments enjoyed no apparent efficacious advantage over those who were not receiving these drugs.

The efficacy results are also consistent with those reported for infliximab ${ }^{33}{ }^{49}$; however, no antibodies to etanercept were found in this study. The lack of etanercept immunogenicity in this trial might be explained by the trial's brevity, and the frequency of etanercept antibodies after long term treatment in patients with AS is unknown. It is noteworthy, however, that in etanercept trials of up to 2 years in patients with RA, the level of etanercept antibody reactivity has been reported to be around 3\%. ${ }^{50}{ }^{51}$ Additionally, these results contrast with the recent finding of a study of infliximab to treat Crohn's disease, in which $61 \%$ of patients produced antibodies to infliximab after a mean of 3.9 infusions of $5 \mathrm{mg} / \mathrm{kg}$ over a mean of 10 months. In the latter study, antibody concentrations $\geqslant 8.0 \mu \mathrm{g} / \mathrm{ml}$ significantly reduced serum concentrations of infliximab, which in turn significantly decreased the duration of treatment response. ${ }^{52}$

Etanercept was well tolerated in adult patients with AS. Although approximately one third of patients had injection site reactions, no serious infections occurred, and no patients withdrew because of these reactions or other adverse events. Etanercept's safety profile was similar to that seen in patients with RA and PsA. Although pharmacokinetic measures from the current study are not shown in this article, a separate analysis of clearance and steady state trough concentrations showed that etanercept's pharmacokinetic profile in patients with AS was similar to that in patients with $\mathrm{RA}^{53}$; thus, it appears that the disposition of etanercept is unaltered by the AS disease state.

As noted above the socioeconomic burden of AS can be considerable. Thus, the relatively higher cost of etanercept treatment compared with less efficacious treatments should be weighed against the costs of AS disease.

In summary, etanercept produced a rapid and sustained reduction of the clinical signs and symptoms of AS. Given these results, further investigation of longer term treatment with etanercept is warranted to further define its therapeutic utility. The use of imaging tools also is warranted to investigate the effects of etanercept on spinal disease, and such tests may shed light on whether etanercept can halt the progression of AS.

\section{ACKNOWLEDGEMENTS}

This trial was funded by Wyeth Research.

Ron Pedersen, an employee of Wyeth, is acknowledged for his study design advice and statistical analysis. Susan Coyle, an employee of Wyeth, is acknowledged for her writing support.

\section{Authors' affiliations}

A Calin, Royal National Hospital for Rheumatic Diseases, Upper Borough Walls, Bath BA1 1RL, UK

B A C Dijkmans, AZ Vrije Universiteit, Amsterdam, The Netherlands

P Emery, Leeds General Infirmary, Leeds, UK

M Hakala, Rheumatism Foundation Hospital, Heinola, Finland

J Kalden, University Hospital Erlangen-Nuremberg, Erlangen, Germany

M Leirisalo-Repo, Helsinki University Central Hospital, Helsinki, Finland

E M Mola, Hospital La Paz, Madrid, Spain

C Salvarani, Arcispedale S. Maria Nuova, Reggio Emilia, Italy

R Sanmartí, Hospital Clínic i Provincial, Barcelona, Spain

J Sany, Hôpital Lapeyronie, Montpellier, France

J Sibilia, Hôpital Hautepierre, Strasbourg, France

J Sieper, University Hospital Benjamin Franklin, Berlin, Germany

$\mathbf{S}$ van der Linden, Academisch Ziekenhuis, Maastricht, The Netherlands E Veys, UZ Gent, Gent, Belgium

A M Appel, S Fatenejad, Wyeth Research, Collegeville, PA, USA

Presented in part at the Annual European Congress of Rheumatology in Lisbon, Portugal, June 2003.

\section{REFERENCES}

1 Braun J, Sieper J. Therapy of ankylosing spondylitis and other spondyloarthritides: established medical treatment, anti-TNF therapy and other novel approaches. Arthritis Res 2002;4:307-21.

2 Will R, Edmunds L, Elswood J, Calin A. Is there sexual inequality in ankylosing spondylitis? A study of 498 women and 1202 men. J Rheumatol 1990; 17:1649-52.

3 Kennedy LG, Edmunds L, Calin A. The natural history of ankylosing spondylitis: does it burn out? J Rheumatol 1993;20:688-92.

4 Ringsdal VS, Andreasen JJ. Ankylosing spondylitis-experience with a self administered questionnaire: an analytical study. Ann Rheum Dis 1989;48:924-7.

5 Ward MM. Health-related quality of life in ankylosing spondylitis: a survey of 175 patients. Arthritis Care Res 1999; 12:247-55.

6 Taylor AL, Balakrishnan C, Calin A. Reference centile charts for measures of disease activity, functional impairment, and metrology in ankylosing spondylitis. Arthritis Rheum 1998;41:1119-25.

7 Goodacre JA, Mander M, Dick WC. Patients with ankylosing spondylitis show individual patterns of variation in disease activity. $\mathrm{Br} J$ Rheumatol 1991;30:336-8.

8 Braun J, Pincus T. Mortality, course of disease, and prognosis of patients with ankylosing spondylitis. Clin Exp Rheumatol 2002;20:S16-22.

9 Gran JT, Skomsvoll JF. The outcome of ankylosing spondylitis: a study of 100 patients. Br J Rheumatol 1997;36:766-71.

10 Barlow JH, Wright CC, Williams B, Keat A. Work disability among people with ankylosing spondylitis. Arthritis Care Res 2001;45:424-9.

11 Ward MM. Functional disability predicts total costs in patients with ankylosing spondylitis. Arthritis Rheum 2002;46:223-31.

12 Grom AA, Murray KJ, Luyrink L, Emery H, Passo MH, Glass DN, et al. Patterns of expression of tumor necrosis factor alpha, tumor necrosis factor beta, and their receptors in synovia of patients with juvenile rheumatoid arthritis and juvenile spondylarthropathy. Arthritis Rheum 1996;39:1703-10.

13 Boonen A. Socioeconomic consequences of ankylosing spondylitis. Clin Exp Rheumatol 2002;20:S23-6.

14 Clegg DO, Reda DJ, Weisman MH, Blackburn WD, Cush JJ, Cannon GW, et al. Comparison of sulfasalazine and placebo in the treatment of ankylosing spondylitis: a Department of Veterans Affairs cooperative study. Arthritis Rheum 1996;39:2004-12.

15 Dougados M, van der Linden S, Leirisalo-Repo M, Huitfeldt B, Juhlin R, Veys E, et al. Sulfasalazine in the treatment of spondylarthropathy: a randomized, multicenter, double-blind, placebo-controlled study. Arthritis Rheum 1995;38:618-27.

16 Biasi D, Carletto A, Caramaschi P, Pacor ML, Maleknia T, Bambara LM. Efficacy of methotrexate in the treatment of ankylosing spondylitis: a threeyear open study. Clin Rheumatol 2000;19:114-17.

17 Roychowdhury B, Bintley-Bagot S, Bulgen DY, Thompson RN, Tunn EJ, Moots RJ. Is methotrexate effective in ankylosing spondylitis? Rheumatology (Oxford) 2002;41:1330-2

18 Maksymowych WP. Novel therapies in the treatment of spondyloarthritis Expert Opin Investig Drugs 2002;11:937-46.

19 Toussirot E, Lafforgue P, Boucraut J, Despieds P, Schiano A, Bernard D, et al. Serum levels of interleukin 1-beta, tumor necrosis factor-alpha, soluble interleukin 2 receptor and soluble cd8 in seronegative spondylarthropathies. Rheumatol Int 1994;13:175-80.

20 Gratacos J, Collado A, Filella X, Sanmarti R, Canete J, Llena J, et al. Serum cytokines (IL-6, TNF-alpha, IL-1 beta and IFN-gamma) in ankylosing spondylitis: a close correlation between serum IL-6 and disease activity and severity. Br J Rheumatol 1994;33:927-31.

21 Braun J, Bollow M, Neure L, Seipelt E, Seyrekbasan F, Herbst H, et al. Use of immunohistologic and in situ hybridization techniques in the examination of sacroiliac joint biopsy specimens from patients with ankylosing spondylitis. Arthritis Rheum 1995;38:499-505.

22 Canete JD, Llena J, Collado A, Sanmarti R, Gaya A, Gratacos J, et al. Comparative cytokine gene expression in synovial tissue of early rheumatoid arthritis and seronegative spondylarthropathies. $\mathrm{Br} J$ Rheumato 1997;36:38-42.

23 Arend WP. The mode of action of cytokine inhibitors. J Rheumatol Suppl 2002;65:16-21.

24 Fernandez-Botran R. Soluble cytokine receptors: novel immunotherapeutic agents. Expert Opin Investig Drugs 2000;9:497-514.

25 Moreland LW, Schiff MS, Baumgartner SW, Tindall EA, Fleischmann RM Bulpitt KJ, et al. Etanercept therapy in rheumatoid arthritis: a randomized, controlled trial. Ann Intern Med 1999;130:478-86.

26 Lovell DJ, Giannini EH, Reiff A, Cawkwell GD, Silverman ED, Nocton JJ, et al. Etanercept in children with polyarticular juvenile rheumatoid arthritis. N Engl J Med 2000;342:763-9.

27 Mease PJ, Goffe BS, Metz J, VanderStoep A, Finck B, Burge DJ. Etanercept in the treatment of psoriatic arthritis and psoriasis: a randomised trial. Lancet 2000;356:385-90

28 Gorman JD, Sack KE, Davis JC Jr. Treatment of ankylosing spondylitis by inhibition of tumor necrosis factor $\alpha$. N Engl J Med 2002;346:1349-56.

29 Flores D, Marquez J, Garza M, Espinoza LR. Reactive arthritis: newer developments. Rheum Dis Clin North Am 2003;29:37-59.

30 Brandt J, Khariouzov A, Listing J, Haibel H, Sorensen H, Grassnickel L, et al. Six-month results of a double-blind, placebo-controlled trial of etanercept treatment in patients with active ankylosing spondylitis. Arthritis Rheum 2003;48: 1667-75

31 Davis JC, Woolley JM. Improvements in patient-reported outcomes for subjects with ankylosing spondylitis receiving etanercept therapy [abstract]. Ann Rheum Dis 2003;62(suppl I):252. 
32 Van den Bosch F, Kruithof E, Baeten D, Herssens A, de Keyser F, Mielants H, et al. Randomized double-blind comparison of chimeric monoclonal antibody to tumor necrosis factor alpha (infliximab) versus placebo in active spondylarthropathy. Arthritis Rheum 2002;46:755-65.

33 Braun J, Brandt J, Listing J, Zink A, Alten R, Golder W, et al. Treatment of active ankylosing spondylitis with infliximab: a randomised controlled multicentre trial. Lancet 2002;359:1187-93.

34 Anderson JJ, Baron G, van der Heijde D, Felson DT, Dougados M. Ankylosing spondylitis assessment group preliminary definition of short-term improvement in ankylosing spondylitis. Arthritis Rheum 2001;44:1876-86.

35 Davis JC Jr, van der Heijde D, Braun J, Dougados M, Cush J, Clegg DO, et al Recombinant human tumor necrosis factor receptor (etanercept) for treating ankylosing spondylitis. Arthritis Rheum 2003:48:3230-6.

36 van der Linden S, Valkenburg HA, Cats A. Evaluation of diagnostic criteria for ankylosing spondylitis. A proposal for modification of the New York criteria. Arthritis Rheum 1984;27:361-8.

37 Garrett S, Jenkinson T, Kennedy LG, Whitelock H, Gaisford P, Calin A. A new approach to defining disease status in ankylosing spondylitis: the Bath Ankylosing Spondylitis Disease Activity Index. J Rheumatol 1994;21:2286-91.

38 Calin A, Garrett S, Whitelock H, Kennedy LG, O'Hea J, Mallorie P, et al. A new approach to defining functional ability in ankylosing spondylitis: the development of the Bath Ankylosing Spondylitis Functional Index. J Rheumatol 1994;21:2281-5

39 Moreland LW, Margolies G, Heck Jr LW, Saway A, Blosch C, Hanna R, et al Recombinant soluble tumor necrosis factor receptor (p80) fusion protein: toxicity and dose finding trial in refractory rheumatoid arthritis. J Rheumatol 1996;23:1849

40 Rudwaleit M, Listing J, Brandt J, Braun J, Sieper J. Prediction of a major clinical response (BASDAI 50) to TNF alpha blockers in ankylosing spondylitis [abstract]. Ann Rheum Dis, 2003;62, (suppl I):242.

41 Davis J, Devries T. Predicting treatment response to biologic agents in ankylosing spondylitis [abstract]. Ann Rheum Dis 2003;62(suppl I):36.

42 Braun J, Pham T, Sieper J, Davis J, Van der Linden S, Dougados M, et al. International ASAS consensus statement for the use of anti-tumour necrosis factor agents in patients with ankylosing spondylitis. Ann Rheum Dis 2003;62:817-24.
43 Dougados M, Woolley JM, Tsuji W. Etanercept reduces fatigue in subjects with ankylosing spondylitis [abstract]. Ann Rheum Dis 2003;62(suppl I):244.

44 van Tubergen A, Coenen J, Landewe R, Spoorenberg A, Chorus A, Boonen A, et al. Assessment of fatigue in patients with ankylosing spondylitis: a psychometric analysis. Arthritis Rheum 2002;47:8-16.

45 Maksymowych WP, Breban M, Braun J. Ankylosing spondylitis and current disease-controlling agents: do they work? Best Pract Res Clin Rheumatol 2002;16:619-30.

46 Marzo-Ortega H, McGonagle D, O'Connor P, Emery P. Efficacy of etanercept in the treatment of the entheseal pathology in resistant spondylarthropathy: a clinical and magnetic resonance imaging study. Arthritis Rheum 2001;44:2112-17.

47 Abuzakouk M, Feighery C, Jackson J. Tumour necrosis factor blocking agents: a new therapeutic modality for inflammatory disorders. Br J Biomed Sci 2002:59:173-9.

48 Braun J, Sieper J, Breban M, Collantes-Estevez E, Davis J, Inman R, et al. Antitumour necrosis factor alpha therapy for ankylosing spondylitis: international experience. Ann Rheum Dis 2002;61(suppl III):iii51-60.

49 Maksymowych WP, Jhangri GS, Lambert RG, Mallon C, Buenviaje $\mathrm{H}_{\text {, }}$ Pedrycz $\mathrm{E}$, et al. Infliximab in ankylosing spondylitis: a prospective observational inception cohort analysis of efficacy and safety. J Rheumatol 2002;29:959-65

50 Bathon JM, Martin RW, Fleischmann RM, Tesser JR, Schiff MH, Keystone EC, et al. A comparison of etanercept and methotrexate in patients with early rheumatoid arthritis. N Engl J Med 2000;343:1586-93

51 Genovese MC, Bathon JM, Martin RW, Fleischmann RM, Tesser JR, Schiff MH, et al. Etanercept versus methotrexate in patients with early rheumatoid arthritis. Arthritis Rheum 2002;46:1445-50.

52 Baert F, Noman M, Vermeire S, Van Assche G, D'Haens G, Carbonez A, et al. Influence of immunogenicity on the long-term efficacy of infliximab on Crohn's disease. N Engl J Med 2003;348:601-8.

53 Zhou H, Buckwalter M, Boni J, Wajdula J, Fatenejad S, Raible D, et al. Pharmacokinetics (PK) of etanercept in ankylosing spondylitis (AS) patients were similar to those in rheumatoid arthritis (RA) patients [abstract]. Ann Rheum Dis 2003;62(suppl I):416. 